\title{
Fixed Bed Adsorption Study on Phosphate Removal Using Nanosized FeOOH-Modified Anion Resin
}

\author{
Nan Li, ${ }^{1}$ Jing Ren, ${ }^{1}$ Lin Zhao, ${ }^{1}$ and Zhong-liang Wang ${ }^{2}$ \\ ${ }^{1}$ School of Environmental Science and Engineering, Tianjin University, Tianjin 300072, China \\ ${ }^{2}$ Tianjin Key Laboratory of Water Resources and Environment, Tianjin Normal University, No. 393 Binshuixi Road, \\ Xiqing District, Tianjin 300387, China \\ Correspondence should be addressed to Lin Zhao; bigbigdate@yahoo.com
}

Received 2 May 2013; Accepted 3 June 2013

Academic Editor: Xinqing Chen

Copyright (C) 2013 Nan Li et al. This is an open access article distributed under the Creative Commons Attribution License, which permits unrestricted use, distribution, and reproduction in any medium, provided the original work is properly cited.

\begin{abstract}
Removal of phosphate from solution using nanosized FeOOH-modified anion resin was studied in fixed bed column. Effect of bed height and flow rate on the breakthrough curves were investigated. Longer breakthrough time was obtained by increasing the bed height and decreasing the flow rate. Bed service depth time (BDST) model was applied to recount the relationship between bed service time and bed height. The value of $N_{0}$ was calculated to be $21.4 \mathrm{~g} / \mathrm{L}$. Yoon-Nelson model, which fitted well with the experimental data, is allowable to estimate the breakthrough curves and characteristic parameters for phosphate adsorption in the column filled with nanosized FeOOH-modified anion resin.
\end{abstract}

\section{Introduction}

Phosphorus is an essential nutrient element to agricultural and industrial development. However, the disposal of dissolved phosphate contained in wastewater is a major inducement of water eutrophication all over the world [1]. Several treatment techniques are used in the wastewater treatment industry in large-scale treatment facilities or only in the experimental project. Biological phosphorus removal (BPR) [2], chemical precipitation, and adsorption by functionalized materials [3] are commonly used for phosphorus removal. BPR has been proved to be an economic and efficient technique which is widely applied in wastewater treatment plant [4-6]. Nevertheless, the functional microorganism, which is called phosphorus-accumulating organisms (PAOs), is sensitive to the variation of environmental and operating conditions. Though chemical precipitation is an effective method to remove phosphorus, high cost and generation of metal sludge are major hindrances for its widely application [3]. Adsorption is used widely for phosphorus removal and recovery [7]. The bottleneck for application of adsorption in wastewater treatment is the development of low-cost and efficient adsorbent.
In the previous study, it has been proved that nanosized ferric oxides showed high adsorption performance towards pollutants like chromium, arsenic, plumbum, and phosphate [8-12] due to their large specific surface area [13]. The hybrid adsorbent by loading nanosized ferric oxyhydroxide on anion resin has indicated efficient adsorption performance for phosphorus removal [14-17]. However, little knowledge is obtained about continuous flow fixed bed experiment adsorption which is necessary to investigate the performance of practical operation [18].

The main objective of the present study is to investigate the adsorption of phosphate in fixed bed column filled with nanosized $\mathrm{FeOOH}$-modified anion resin. Effect of several important design parameters such as bed height, flow rate, and initial concentration of phosphate in solution was investigated. In addition, bed depth service time (BDST) and YoonNelson model were applied to fit with the data obtained from fixed bed study.

\section{Materials and Methods}

2.1. Preparation of Nanosized FeOOH-Modified Anion Resin and Phosphate Solution. The nanosized FeOOH-modified 
anion resin adsorbent was prepared by loading nanosized ferric oxyhydroxide onto anion resin according to the method reported in previous study in our lab [17].

All chemicals used were analytical grade. Phosphate stock solution $(50 \mathrm{mg} / \mathrm{L})$ was prepared by dissolving $\mathrm{KH}_{2} \mathrm{PO}_{4}$ into distilled water. The stock solution was diluted to obtain phosphate solution of different concentrations.

2.2. Fixed Bed Column Experiments. Bulk removal of phosphate onto nanosized FeOOH-modified anion resin was investigated in a fixed bed column $(10 \mathrm{~mm}$ in diameter and $300 \mathrm{~mm}$ in length). To maintain a constant flow of the fixed bed column, a constant flow variable speed peristaltic pump (Longer-BT100) was equipped. The upflow of solution was introduced at the bottom of the column. Liquid samples were collected at regular time intervals at the exit of the fixed bed column for phosphate concentration analysis.

2.3. Analyses and Calculation. The concentrations of phosphate in the fixed bed adsorption experiments were determined according to standard methods for the examination of water and wastewater [19]. Nanosized FeOOH-modified anion resin samples were analysed by a scanning electron microscope (SEM, Nanosem 430, FEI Inc., USA).

2.4. BDST Model. The BDST model which is based on Bohart-Adams equation was commonly applied to depict the relationship between bed depth and service time at fixed bed adsorption.

The linear form of BDST model can be expressed as follows [20]:

$$
t=\frac{N_{0} Z}{C_{0} v}-\frac{1}{K_{a} C_{0}} \ln \left(\frac{C_{0}}{C_{t}}-1\right),
$$

where $N_{0}$ is the adsorption capacity of fixed bed column $(\mathrm{mg} / \mathrm{L}), Z$ is the bed height of column $(\mathrm{cm}), C_{0}$ represents the initial phosphate concentration $(\mathrm{mg} / \mathrm{L}), C_{t}$ represents the phosphate concentration at time $t(\mathrm{mg} / \mathrm{L}), v$ is the linear flow rate of solution through the bed $(\mathrm{cm} / \mathrm{min}), t$ is the service time of column ( $\mathrm{min})$, and $K_{a}$ is the rate constant $(\mathrm{L} / \mathrm{mg} \cdot \mathrm{min})$.

2.5. Yoon-Nelson Model. Yoon-Nelson model is a less complicated model which can be used to investigate the adsorption and breakthrough curves in fixed bed column [21]. This model is based on the hypothesis that the probability of adsorption decrease rate of each adsorbate molecule is linearly related to the probability of amount of adsorbate adsorption and breakthrough on the adsorbent [21].

The linear form of Yoon-Nelson model is represented as follows [22]:

$$
\ln \left(\frac{C_{t}}{C_{0}-C_{t}}\right)=k_{\mathrm{YN}} t-\tau k_{\mathrm{YN}},
$$

where $k_{\mathrm{YN}}$ is the Yoon-Nelson rate constant $\left(\mathrm{min}^{-1}\right), \tau$ is the breakthrough time required for $50 \%$ adsorbate breakthrough (min). The values of $k_{\mathrm{YN}}$ and $\tau$ can be determined by the linear plot of $\ln \left(C_{t} /\left(C_{0}-C_{t}\right)\right)$ against $t$.

\section{Results and Discussion}

3.1. Characterization of Nanosized FeOOH-Modified Anion Resin. The nanosized FeOOH-modified anion resin was deep brown spherical adsorbent bead, which was quite different from the white spherical bead of anion resin. The SEM images have clearly indicated that after preparation of nanosized $\mathrm{FeOOH}$-modified anion resin, nanosized Fe had been successfully loaded on anion resin (Figure 1). After FeOOH loading, the adsorption capacity of anion resin increased from 38.70 to $51.52 \mathrm{mg} / \mathrm{g}$. by the formation of inner-sphere surface complexes between phosphate and FeOOH $[23,24]$.

The adsorption performance of nanosized $\mathrm{FeOOH}$ modified anion resin was much better than some other kinds of anion resin (with adsorption capacity of 12.09 [25], 20.9 [26], and $26.5 \mathrm{mg} / \mathrm{g}$ [27], resp.).

3.2. Effect of Bed Height. Effect of bed height on the fixed bed adsorption was investigated at a constant initial concentration of $20 \mathrm{mg} / \mathrm{L}$ phosphate in solution. The flow rate of influent was set at $10 \mathrm{~mL} / \mathrm{min}$. Breakthrough concentration $\left(C_{b}\right)$ is fixed at $10 \%$ of the initial concentration $\left(C_{0}\right)$. The breakthrough curves were obtained by varying bed heights from $5 \mathrm{~cm}$ to $15 \mathrm{~cm}$ (Figure 2.) It was observed that the breakthrough time increased from 300 to $1140 \mathrm{~min}$ with the increase of bed height. Besides, the exhaustion time increased from 720 to $2100 \mathrm{~min}$. The increase of breakthrough time and exhaustion time was due to more nanosized $\mathrm{FeOOH}$ modified anion resin filling in column with higher bed height, which provide greater functional sites and broadened mass transfer zone for phosphate adsorption.

The BDST model was applied to predict the phosphate adsorption in column filled with nanosized $\mathrm{FeOOH}$ modified anion resin. According to (1), $C_{0}$ and $v$ are assumed to be reasonably constant for fixed bed adsorption. The values of $N_{0}$ and $K_{a}$ are calculated to be $21.4 \mathrm{~g} / \mathrm{L}$ and $5.43 \times$ $10^{-3} \mathrm{~L} / \mathrm{mg} \cdot \mathrm{min}$, respectively.

3.3. Effect of Flow Rate. Fixed bed adsorption experiments were operated at different flow rate in columns filled with nanosized FeOOH-modified anion resin. The breakthrough curves for fixed bed column adsorption at different flow rates were given in Figure 3. The breakthrough of fixed bed column for flow rates 5,10 , and $15 \mathrm{~mL} / \mathrm{min}$ occurred at 1320, 720, and $420 \mathrm{~min}$, respectively. The breakthrough time decreased with the increase of flow rate, because of more phosphate exchanging with functional group sites in shorter time. The flow rate also influences the shape of breakthrough curve. The steeper breakthrough curve was observed at higher flow rate, indicating a more prominent effect of intraparticle diffusion and shorter service time of fixed bed column.

3.4. Yoon-Nelson Model. The Yoon-Nelson model was applied to predict the adsorption process and breakthrough curves. Calculated according to linearized Yoon-Nelson equation, $k_{\mathrm{YN}}$ decreased and $\tau$ increased with increase of bed height (Figure 4(a) and Table 1). In contrast, when the flow rate increased from 5 to $15 \mathrm{~mL} / \mathrm{min}$, the value of $k_{\mathrm{YN}}$ 


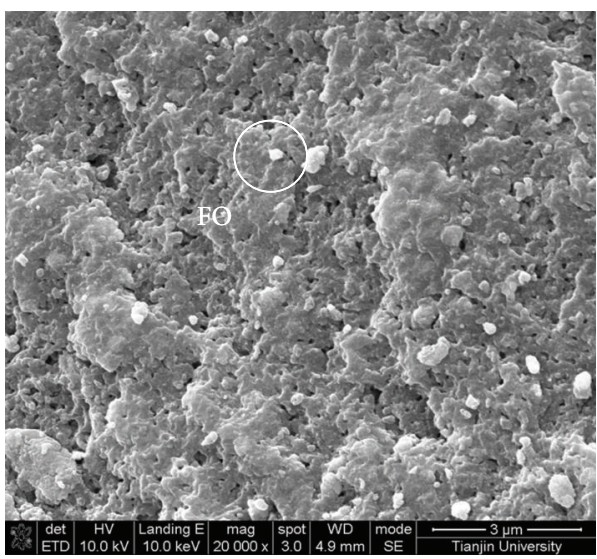

(a)

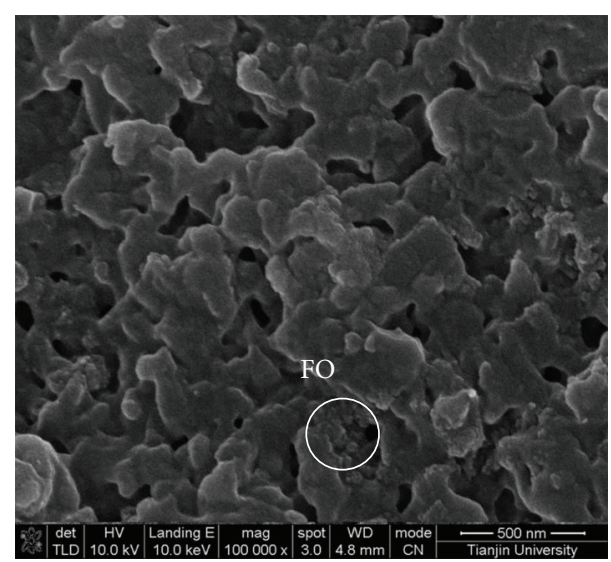

(b)

FIGURE 1: SEM micrograph of nanosized FeOOH-modified anion resin.

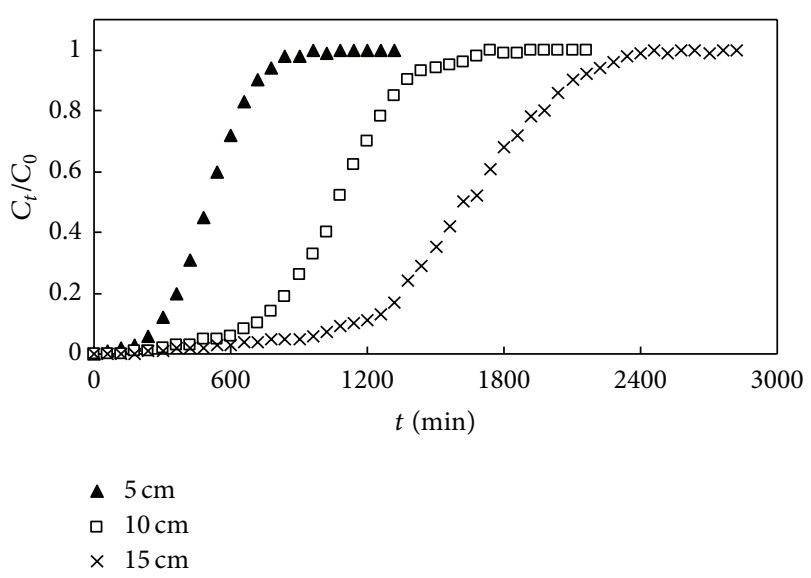

FIGURE 2: Effect of bed height on phosphate adsorption in column filled with nanosized $\mathrm{FeOOH}-$ modified anion resin. (Conditions: initial phosphate concentration $20 \mathrm{mg} / \mathrm{L}$; flow rate $10 \mathrm{~mL} / \mathrm{min}$.)

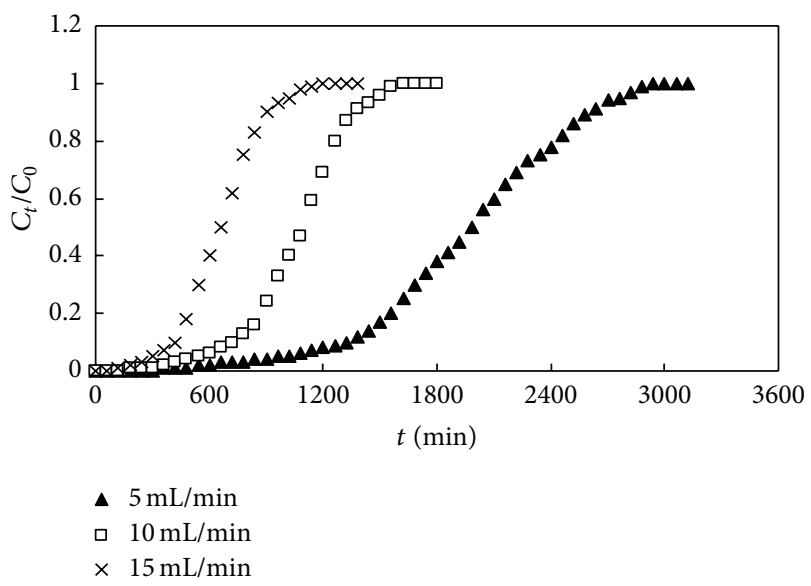

FIGURE 3: Effect of flow rate on phosphate adsorption in column filled with nanosized $\mathrm{FeOOH}$-modified anion resin. (Conditions: initial phosphate concentration $20 \mathrm{mg} / \mathrm{L}$; beh height $10 \mathrm{~cm}$.)
TABLE 1: Yoon-Nelson model parameters for fixed bed adsorption of phosphate in column filled with nanosized $\mathrm{FeOOH}$-modified anion resin.

\begin{tabular}{lcccccc}
\hline $\begin{array}{l}Q \\
(\mathrm{~mL} / \mathrm{min})\end{array}$ & $\begin{array}{c}Z \\
\mathrm{Cm})\end{array}$ & $\begin{array}{c}C_{0} \\
(\mathrm{mg} / \mathrm{L})\end{array}$ & $\begin{array}{c}k_{\mathrm{YN}} \\
\left(\mathrm{min}^{-1}\right)\end{array}$ & $\begin{array}{c}\tau_{\text {theo }} \\
(\mathrm{min})\end{array}$ & $\begin{array}{c}\tau_{\exp } \\
(\mathrm{min})\end{array}$ & $R^{2}$ \\
\hline 5 & 10 & 20 & 0.0028 & 2030.4 & 1980 & 0.9883 \\
10 & 10 & 20 & 0.0053 & 1109.8 & 1140 & 0.9899 \\
15 & 10 & 20 & 0.0084 & 659.7 & 660 & 0.9972 \\
10 & 5 & 20 & 0.0105 & 498.0 & 540 & 0.9976 \\
10 & 10 & 20 & 0.0054 & 1069.8 & 1080 & 0.9873 \\
10 & 15 & 20 & 0.0031 & 1745.8 & 1680 & 0.9752 \\
\hline
\end{tabular}

increased from 0.028 to $0.0084 \mathrm{~min}^{-1}$ (Figure 4(b) and Table 1). Accordingly, the value of $\tau$ decreased from 2030.4 to $659.7 \mathrm{~min}$. The theoretical breakthrough time $\tau_{\text {theo }}$ required for $50 \%$ adsorbate breakthrough was very close to the $\tau_{\text {exp }}$, which proved that the Yoon-Nelson model fitted well with the experimental data for phosphate adsorption in column filled with nanosized $\mathrm{FeOOH}$-modified anion resin.

\section{Conclusion}

Continuous adsorption of phosphate from aqueous solution was experimentally and theoretically studied in fixed bed columns filled with nanosized FeOOH-modified anion resin. Both breakthrough time and exhaustion time increased with increase of bed height. In contrast, the breakthrough time decreased from 1320 to $420 \mathrm{~min}$ with increase of the flow rate from 5 to $15 \mathrm{~mL} / \mathrm{min}$. According to BDST model, the adsorption capacity $N_{0}$ was calculated to be $21.4 \mathrm{~g} / \mathrm{L}$. Steeper breakthrough curves were observed at lower bed height. It has been observed that Yoon-Nelson model fitted well with experimental data with high correlation coefficient, which proved that Yoon-Nelson model is allows to estimating the breakthrough curves and characteristic parameters of the column. 


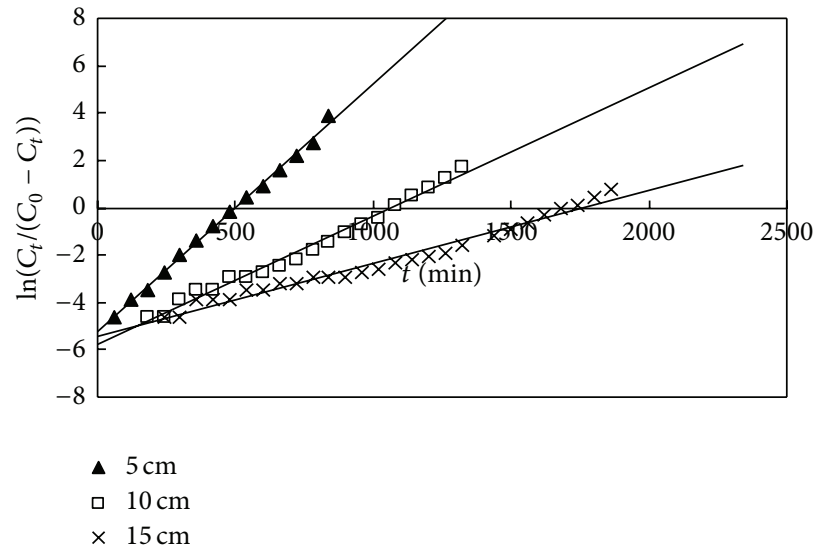

(a)

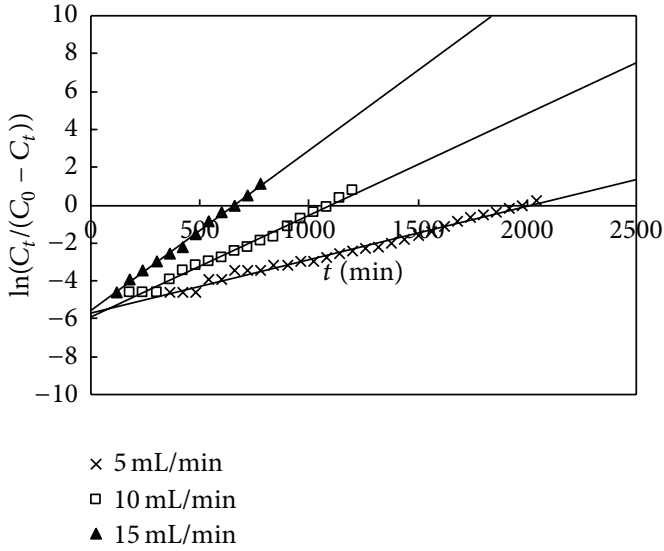

(b)

FIGURE 4: Yoon-Nelson model for phosphate adsorption in column filled with nanosized FeOOH-modified anion resin at (a) different bed height, and (b) different flow rate.

\section{Acknowledgments}

This research was supported by the National Natural Science Foundation of China (no. 51208352 and no. 21076140), the Natural Science Foundation of Tianjin (no. 13JCQNJC09100), and the Opening Fund of Tianjin Key Laboratory of Water Resources and Environment, Tianjin Normal University (no. 52XS1203).

\section{References}

[1] Y. Shintaro and F. Keisuke, "Removal of phosphate from solution by adsorption and precipitation of calcium phosphate onto monohydrocalcite," Journal of Colloid and Interface Science, vol. 384, no. 1, pp. 128-136, 2012.

[2] Y. Wu, T. Li, and L. Yang, "Mechanisms of removing pollutants from aqueous solutions by microorganisms and their aggregates: a review," Bioresource Technology, vol. 107, pp. 10-18, 2012.

[3] M. S. Onyango, D. Kuchar, M. Kubota, and H. Matsuda, "Adsorptive removal of phosphate ions from aqueous solution using synthetic zeolite," Industrial and Engineering Chemistry Research, vol. 46, no. 3, pp. 894-900, 2007.

[4] J. Ma, Y. Z. Peng, S. Y. Wang, L. Wang, Y. Liu, and N. P. Ma, "Denitrifying phosphorus removal in a step-feed CAST with alternating anoxic-oxic operational strategy," Journal of Environmental Sciences, vol. 21, no. 9, pp. 1169-1174, 2009.

[5] C. Chen, P. Zhang, G. Zeng, J. Deng, Y. Zhou, and H. Lu, "Sewage sludge conditioning with coal fly ash modified by sulfuric acid," Chemical Engineering Journal, vol. 158, no. 3, pp. 616-622, 2010.

[6] H. Li and Y. Chen, "Research on polyhydroxyalkanoates and glycogen transformations: key aspects to biologic nitrogen and phosphorus removal in low dissolved oxygen systems," Frontiers of Environmental Science and Engineering in China, vol. 5, no. 2, pp. 283-290, 2011.

[7] Y. Li, C. Liu, Z. Luan et al., "Phosphate removal from aqueous solutions using raw and activated red mud and fly ash," Journal of Hazardous Materials, vol. 137, no. 1, pp. 374-383, 2006.

[8] C. Xu, D. Cheng, B. Gao, Z. Yin, Q. Yue, and X. Zhao, "Preparation and characterization of $\beta-\mathrm{FeOOH}$-coated sand and its adsorption of $\mathrm{Cr}(\mathrm{VI})$ from aqueous solutions," Frontiers of Environmental Science and Engineering in China, vol. 6, no. 4, pp. 455-462, 2012.

[9] S. Dixit and J. G. Hering, "Comparison of $\operatorname{arsenic}(V)$ and arsenic(III) sorption onto iron oxide minerals: implications for arsenic mobility," Environmental Science and Technology, vol. 37, no. 18, pp. 4182-4189, 2003.

[10] A. C. Scheinost, S. Abend, K. I. Pandya, and D. L. Sparks, "Kinetic controls on $\mathrm{Cu}$ and $\mathrm{Pb}$ sorption by ferrihydrite," Environmental Science and Technology, vol. 35, no. 6, pp. 10901096, 2001.

[11] L. Zeng, X. Li, and J. Liu, "Adsorptive removal of phosphate from aqueous solutions using iron oxide tailings," Water Research, vol. 38, no. 5, pp. 1318-1326, 2004.

[12] B. Pan, J. Wu, B. Pan et al., "Development of polymer-based nanosized hydrated ferric oxides (HFOs) for enhanced phosphate removal from waste effluents," Water Research, vol. 43, no. 17, pp. 4421-4429, 2009.

[13] C. L. Warner, W. Chouyyok, K. E. Mackie et al., "Manganese doping of magnetic iron oxide nanoparticles: tailoring surface reactivity for a regenerable heavy metal sorbent," Langmuir, vol. 28, no. 8, pp. 3931-3937, 2012.

[14] B. D. Martin, S. A. Parsons, and B. Jefferson, "Removal and recovery of phosphate from municipal wastewaters using a polymeric anion exchanger bound with hydrated ferric oxide nanoparticles," Water Science and Technology, vol. 60, no. 10, pp. 2637-2645, 2009.

[15] L. Cumbal and A. K. SenGupta, "Arsenic removal using polymer-supported hydrated iron(III) oxide nanoparticles: role of Donnan membrane effect," Environmental Science and Technology, vol. 39, no. 17, pp. 6508-6515, 2005.

[16] M. D. Gupta, P. Loganathan, and S. Vigneswaran, "Adsorptive removal of nitrate and phosphate from water by a purolite ion exchange resin and hydrous ferric oxide columns in series," Separation Science and Technology, vol. 47, no. 12, pp. 1785-1792, 2012.

[17] J. Ren, N. Li, and L. Zhao, "Adsorptive removal of Cr(VI) from water by anion exchanger based nanosized ferric oxyhydroxide hybrid adsorbent," Chemical and Biochemical Engineering Quarterly, vol. 26, no. 2, pp. 111-118, 2012. 
[18] K. H. Chu, "Improved fixed bed models for metal biosorption," Chemical Engineering Journal, vol. 97, no. 2-3, pp. 233-239, 2004.

[19] American Public Health Association, American Water Works Association, Water Pollution Control Federation, Standard Methods for the Examination of Water and Wastewater, American Public Health Association, Washington, DC, USA, 19th edition, 1995.

[20] G. McKay and M. J. Bino, "Fixed bed adsorption for the removal of pollutants from water," Environmental Pollution, vol. 66, no. 1, pp. 33-53, 1990.

[21] R. Han, Y. Wang, X. Zhao et al., "Adsorption of methylene blue by phoenix tree leaf powder in a fixed-bed column: experiments and prediction of breakthrough curves," Desalination, vol. 245, no. 1-3, pp. 284-297, 2009.

[22] Y. H. Yoon and J. H. Nelson, "Application of gas adsorption kinetics I. A theoretical model for respirator cartridge service life," American Industrial Hygiene Association Journal, vol. 45, no. 8, pp. 509-516, 1984.

[23] H. Zeng, B. Fisher, and D. E. Giammar, "Individual and competitive adsorption of arsenate and phosphate to a highsurface-area iron oxide-based sorbent," Environmental Science and Technology, vol. 42, no. 1, pp. 147-152, 2008.

[24] G. Lefèvre, "In situ Fourier-transform infrared spectroscopy studies of inorganic ions adsorption on metal oxides and hydroxides," Advances in Colloid and Interface Science, vol. 107, no. 2-3, pp. 109-123, 2004.

[25] M. R. Awual and A. Jyo, "Assessing of phosphorus removal by polymeric anion exchangers," Desalination, vol. 281, no. 1, pp. 111-117, 2011.

[26] H. W. Li, Z. P. Ye, Y. Lin, and F. Y. Wang, "Phosphorus recovery as struvite from eutropic waters by XDA-7 resin," Water Science and Technology, vol. 65, no. 12, pp. 2091-2097, 2012.

[27] L. Ding, C. Wu, H. Deng, and X. Zhang, "Adsorptive characteristics of phosphate from aqueous solutions by MIEX resin," Journal of Colloid and Interface Science, vol. 376, no. 1, pp. 224232, 2012. 

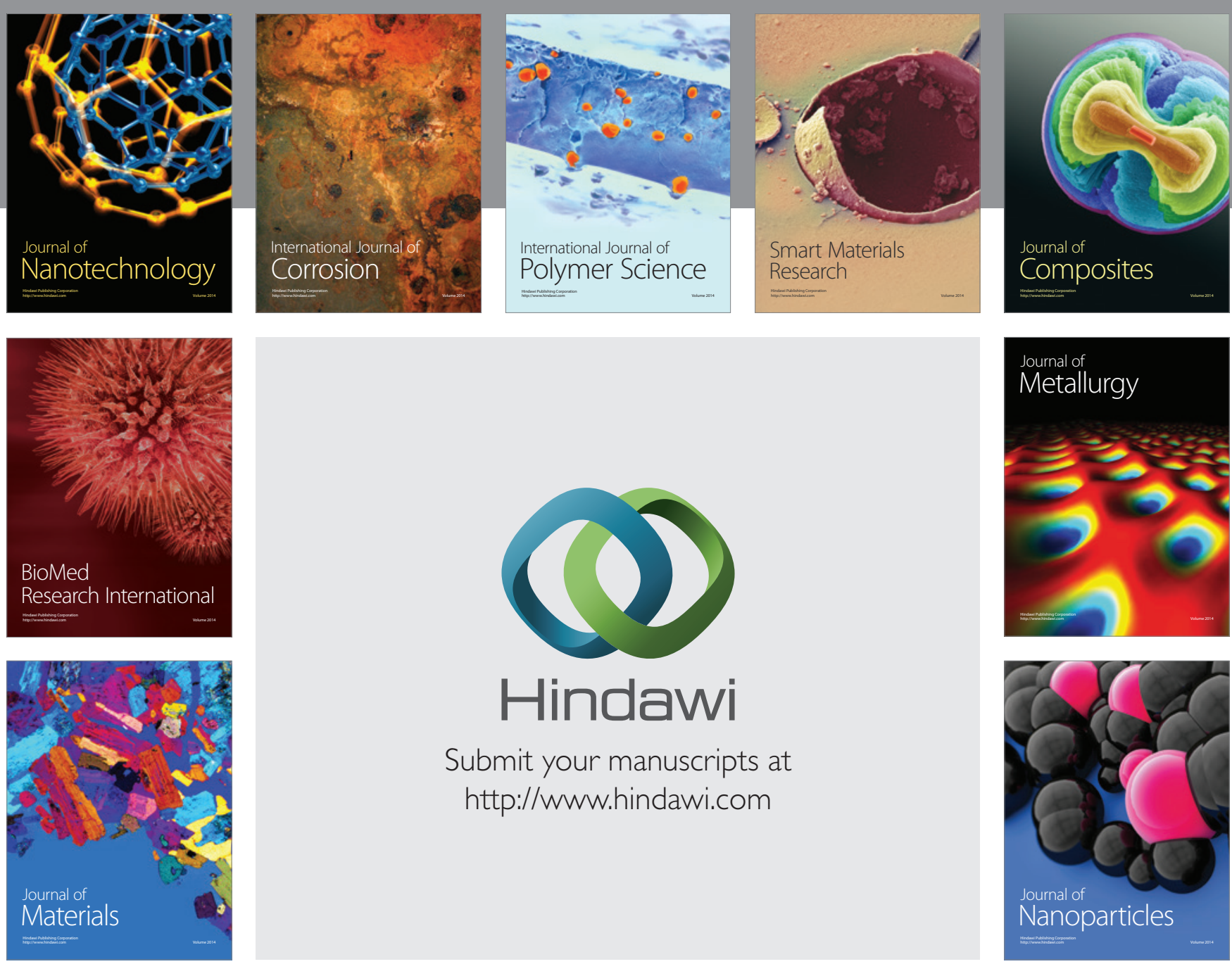

Submit your manuscripts at http://www.hindawi.com
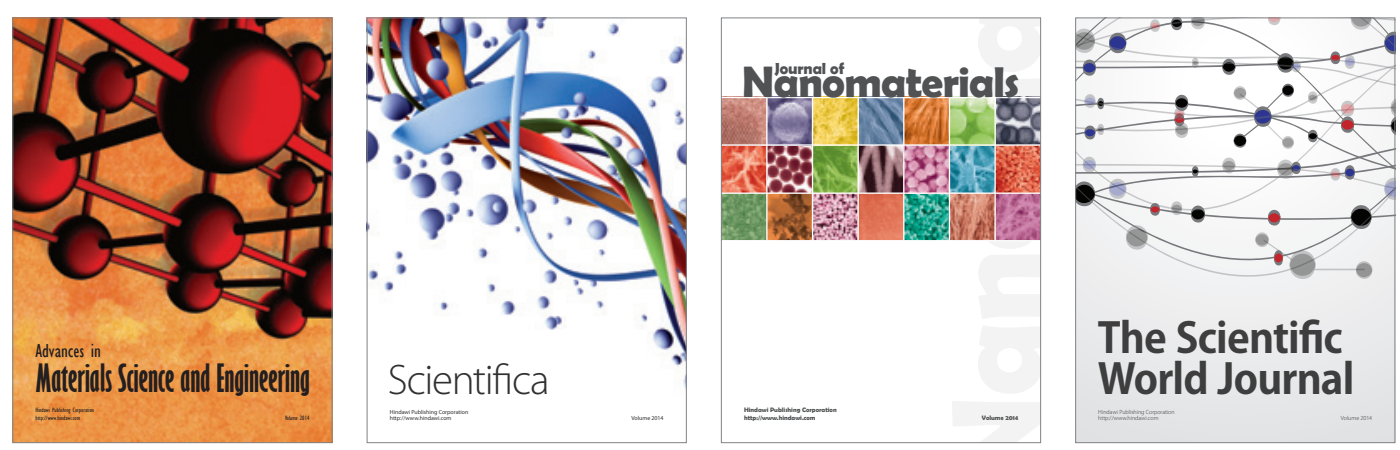

\section{The Scientific World Journal}
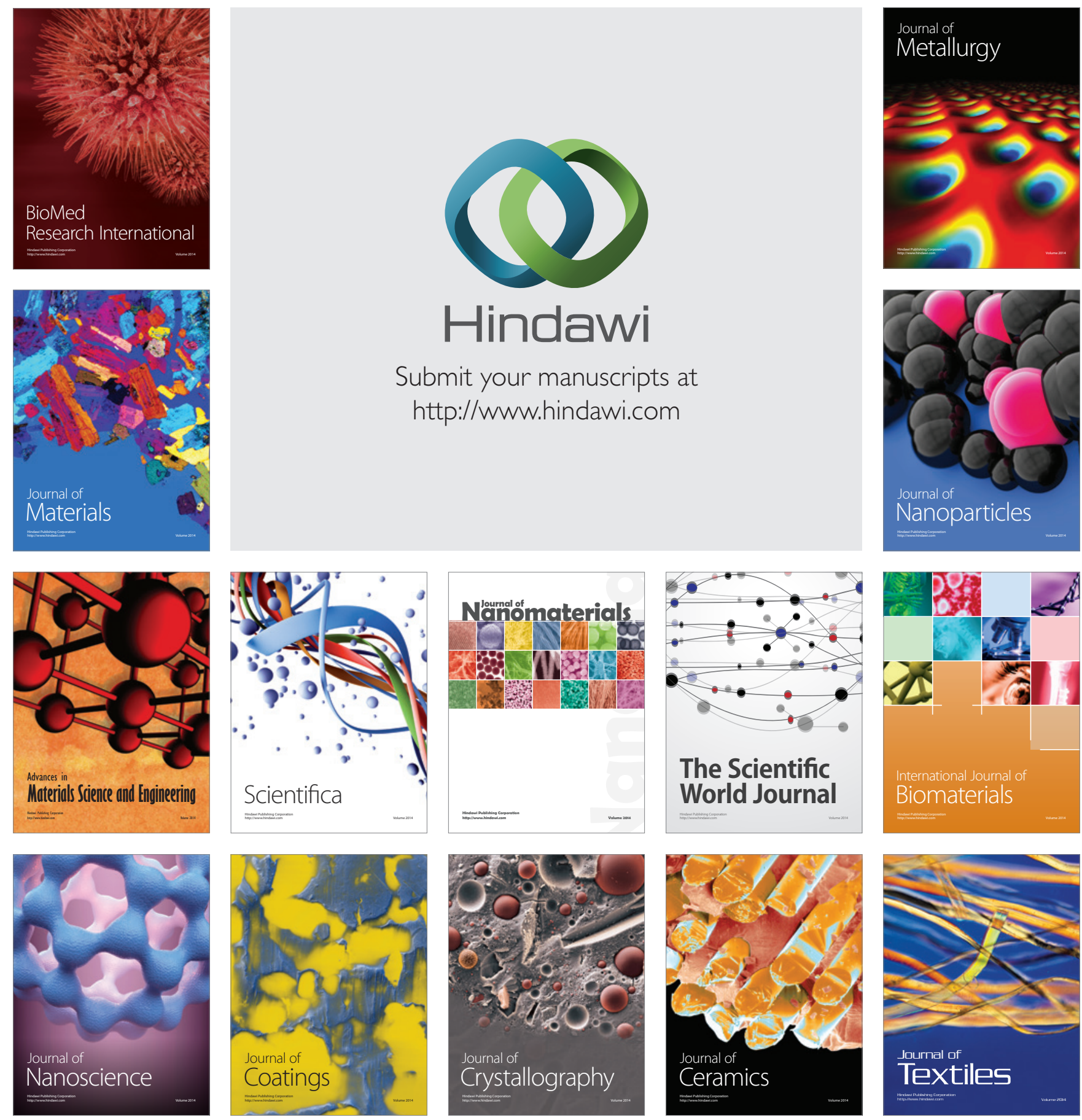